\title{
Assessment of nutrient and water intake among adolescents from sports federations in the Federal District, Brazil
}

\author{
Eliene F. de Sousa ${ }^{1}$, Teresa H. M. Da $\operatorname{Costa}^{2} *$, Julia A. D. Nogueira ${ }^{3}$ and Lúcio J. Vivaldi ${ }^{4}$ \\ ${ }^{1}$ Health Sciences, Faculty of Health Sciences, University of Brasília, Brasilia, Brazil \\ ${ }^{2}$ Department of Nutrition, Faculty of Health Sciences, University of Brasilia, Brasilia, Brazil \\ ${ }^{3}$ Faculty of Physical Education and Faculty of Health Sciences, University of Brasilia, Brasilia, Brazil \\ ${ }^{4}$ Department of Statistics, Institute of Exact Sciences, University of Brasília, Brasília, Brazil
}

(Received 30 March 2007 - Revised 19 September 2007 - Accepted 12 October 2007 - First published online 6 December 2007)

Adolescents aged 11-14 years ( $n$ 326), belonging to organized sports federations in the Federal District, Brazil were interviewed. Subjects $(n$ 107) provided four non-consecutive days of food consumption and 219 subjects provided two non-consecutive days of intake. The objective was to assess their nutrient and water intake according to dietary reference intake values and their energy and macronutrient intake by sex and sports groups they were engaged in: endurance, strength-skill or mixed, according to the guidelines established by the American College of Sport Medicine (ACSM). Dietary data were corrected for intra-individual variation. Total energy expenditure was higher among endurance athletes $(P<0.001)$ following their higher training time $(P<0.001)$ when compared to adolescents engaged in strength-skill or mixed sports. Total energy intake was only significantly higher among endurance-engaged females $(P=0 \cdot 05)$. Protein intake of males was above the guidelines established by the ACSM for all sports groups. All male sport groups fulfilled the intake levels of carbohydrate per kg body weight but only females engaged in endurance sports fulfilled carbohydrate guidelines. Intakes of micronutrients with low prevalence of adequate intake were: vitamins $\mathrm{B}_{1}$, $\mathrm{E}$ and folate, magnesium and phosphorus. Few adolescents $(<5 \%)$ presented adequate intake for calcium, fibre, drinking water and beverages. For micronutrients, prevalence of adequacies were lower for females than males, except for liquids and water. Nutrition guidance is needed to help adolescents fulfil specific guidelines of macronutrient intake for their sports and to improve their intake of micronutrients and water. Special attention should be given to female adolescent athletes.

Dietary assessment: Dietary reference intakes: Water: Vitamins: Minerals: Physical activity: Sports: Adolescents

The bodily changes induced by adolescence increase energy requirements. This higher requirement is not only necessary to maintain health and promote growth and sexual maturation but also to provide the energy expended in physical and intellectual activities ${ }^{(1)}$. The regular practice of sport activities during adolescence can bring health benefits to these individuals. However, the physical activity will increase the energy expenditure and consequently the energy intake needs as well as the need for some nutrients ${ }^{(2)}$. Roemmich $e t$ al. ${ }^{(3)}$ analysed adolescents who practised weight-control sports, such as wrestlers and gymnasts, and found that these individuals presented nutrient intake $50 \%$ below their requirements. These cases of undernutrition among adolescents may lead to changes in growth and sexual maturation. Additionally, these authors justify that, for most adolescents, what impairs their growth and pubertal development is nutrient deficiency, not intense physical activity. In Brazil, the Ministry of Health has launched the National Policy of Health Promotion, which includes the promotion of physical activity and sports practice $^{(4)}$. In schools and sports clubs adolescents are also encouraged to engage in sport activities as a means of physical education and talent selection for sports competition ${ }^{(5)}$.
Nutrient intake, when adequately assessed, is a means of diagnosing the nutritional status of individuals and groups. The set of reference values called dietary reference intakes $(\mathrm{DRI})^{(6)}$ is used to assess and plan diets for healthy individuals and groups of individuals. There are still limited results published using the Institute of Medicine proposed methodology for dietary assessment. The American College of Sports Medicine (ACSM) sets guidelines for nutrient intake to individuals engaged in sport activities ${ }^{(2)}$. Data on the nutritional assessment of adolescent athletes are limited and there are no data published on water and nutrient intake of Brazilian adolescents using the DRI guidelines. As a result, we hypothesized that adolescents engaged in sports will not compromise their intake with existing guidelines for protein and carbohydrate per $\mathrm{kg}$ body weight.

The objectives of the present study were to: (1) determine the prevalence of adequate nutrient and water intake from adolescents of sports federations in the Federal District, Brazil using the set of reference values (estimated average requirement (EAR); adequate intake (AI) and upper tolerable nutrient intake) that constitute the DRI; (2) compare the macronutrient intake of adolescents when grouped into groups of sports that 
require endurance, strength-skill or both, according to reference parameters set by the ACSM; and (3) to verify differences in nutrient intake between the sexes.

\section{Methods}

\section{Subjects}

The sample consisted of athletes of both sexes aged 11-14 years. They were members of official sports federations that organize competitions for this age group in the Federal District, Brazil. The sports included were: athletics (mainly running), swimming, Olympic gymnastics, judo, tennis, volleyball, football, indoor football, handball and basketball. Calculation of the study sample considered a random sample selection with a power of $80 \%$, an error probability of 0.05 and a variance ratio of $0 \cdot 8$. Total sample size was 326 subjects. We selected 336 adolescents and 326 completed the protocol.

Subjects were interviewed in two phases. The first phase lasted from June to December 2003. The second phase lasted from February to May 2004 and 107 adolescents were randomly selected from the initial sample of 326. These 107 also took part in a further protocol to evaluate body composition $^{(7)}$. During both phases, the adolescents maintained normal training and eating patterns. Sample loss was low $(3 \%)$ or non-existent $(0 \%)$ in the first and second phases, respectively. There were 122 female and 204 male adolescent athletes. The sports federations and the University of Brasília Ethics Committee approved the protocol. Each adolescent and parent gave written informed consent prior to participation.

\section{Sports classification}

The classification of sports is arbitrary and often based on the metabolic requirements of training and/or competitions. For the adolescents in the present study, the classification of sports was based on energy requirement and on the predominant motor skills used during the training sessions. The sports were grouped into endurance (swimming and athletics), strengthskill (Olympic gymnastics, judo, tennis and volleyball) and mixed (football, indoor football, handball and basketball). For the purpose of consistency throughout the paper they are going to be called sports groups. Only males participated in football and indoor football. Only females took part in Olympic gymnastics. Both sexes took part in all other sports.

\section{Protocol}

The protocol included activity and dietary questionnaires, and anthropometric assessments. The activity questionnaire obtained information on how many hours the adolescent spent on organized physical activities and training. In brief, the activity questionnaire consisted of fifteen questions, asking: (1) number of hours per day and days per week, including weekends, spent on training; (2) number of hours per day and days per week, including weekends, spent on other organized physical activities; (3) number of hours per day spent sleeping, at school, and on sedentary activities (watching television, playing video games and computer use) during weekdays and weekends. Reported hours of participation in each activity were used to calculate energy expenditure using the Institute of Medicine factorial $\operatorname{method}^{(1)}$. The number of hours per day spent on training was multiplied by the number of days they were performed; therefore, results were presented as hours per week.

Dietary questionnaires included a $24 \mathrm{~h}$ dietary recall and a $1 \mathrm{~d}$ food diary. The $24 \mathrm{~h}$ dietary recall was conducted by trained undergraduate nutrition students according to an interviewer handbook to standardize the way questionnaires were presented and the replies recorded. The adolescents received written notes on how to record the nutritional information of the $1 \mathrm{~d}$ food diary and were encouraged not to change their eating habits.

The consumption of all liquids and foods was recorded during the dietary survey $(24 \mathrm{~h}$ dietary recall and food diary). The adolescents were asked to report the brand or trade name of the products consumed. For meals, they were asked to inform how each meal was prepared (cooked, roasted, fried, etc) and the respective ingredients and amounts. The adolescents were asked to quantify the amount of liquids and foods ingested. This procedure was facilitated by using a set of cooking measurement items (spoons, cups, commercial containers of some products) and also by using a pictorial guide of utensils and food portions ${ }^{(8)}$. Water intake was minutely assessed since it is very difficult to estimate the amount of water ingested outside mealtimes. In order to achieve this, the adolescent was shown a specific cup and asked to specify how much they ingested. If water was ingested from a water fountain, the adolescent was asked to estimate the amount.

The first phase of the research consisted of one $24 \mathrm{~h}$ dietary recall and one food diary. The second phase consisted of two $24 \mathrm{~h}$ dietary recalls, where the second dietary recall was obtained by telephone interview. Thus, at the end of the study, 107 adolescents provided information on four non-consecutive days of food consumption and 219 adolescents provided information on two non-consecutive days of food consumption. All the interviews were supervised by one of the authors. Later a random telephone recheck was conducted for the interviews of each interviewer. The number of errors in this assessment was low (2.9\%), and was mostly related to the record of birth date.

Anthropometric assessments were performed in triplicate accordingly to the Anthropometric Standardization Reference Manual $^{(9)}$ with the subjects wearing light clothing and barefoot, by the same trained anthropometrist. A Plenna scale (model MEA 07400 , USA; accuracy of $100 \mathrm{~g}$ ) was used to determine weight and a Seca stadiometer (model 208, Germany; accuracy of $0.5 \mathrm{~cm}$ ) was used to determine height. Triceps and subscapular skinfolds were measured using a Harpenden caliper (CMS Weighing Equipments, UK) to $\pm 0.2 \mathrm{~mm}$. The average of the closest two measurements was used for analysis. BMI was calculated as weight divided by the square of the height $\left(\mathrm{kg} / \mathrm{m}^{2}\right)$. Body fat $(\%)$ was calculated using the Boileau, Lohman and Slaughter equation ${ }^{(10)}$. This equation was developed for males and females aged 8-29 years old.

\section{Dietary analysis}

The dietary data was coded and entered into the software (NUTRISURVEY for Windows 95 version 5.0, 2002, Germany) by one of the authors and one well-trained researcher to minimize errors. The food database used for this program is based 
on the German Bundeslebensmittelschlüssel, updated in 1999 (version BLS II.3) and locally adapted by incorporating recipes and ingredients listed on Brazilian labels of industrialized foods and food supplements. A guide containing information on how to convert cooking measurements into grams was prepared to standardize the foods consumed and their cooking measurements. The foods that were not in the nutritional analysis software database had to be included using food composition tables ${ }^{(11-13)}$.

\section{Statistical analysis}

The S-Nusser method ${ }^{(14)}$ was used to correct the intra-individual variation in macro- and micronutrient intake ${ }^{(15)}$. The necessary calculations for the corrections were performed by a SAS macro generously supplied by Dr Hoffmann ${ }^{(15)}$ and modified by one of the authors. In summary, the Box-Cox transformation is used during the computational procedure to obtain a roughly normal distribution of the intake data. Intra-individual variation is removed from the individual mean by calculating and applying a factor that flattens the intake distribution. Finally, the corrected measurements return to the original scale, a stage that involves the inverse of the Box-Cox transformation and normal distribution.

The energy and macronutrient intake values are presented as means and standard deviations grouped by types of sports or by sex. The groups were then compared by ANOVA after correcting for intra-individual variation and verifying data normality. Interactions between sex and sport were evaluated. Differences between the means were compared with the Ryan-Einot-Gabriel-Welsch multiple range test $^{(16)}$. The statistics software used was SAS version 8.0 Federal District, Brazil, grouped by sports and sex
(SAS Institute, Cary, NC, USA). The adopted significance level was $5 \%$.

\section{Results}

The proportion of adolescents grouped into endurance, strength-skill and mixed types of sports was 15,34 and $51 \%$, respectively.

Table 1 presents the descriptive and anthropometric data of the adolescents grouped by sports and sex. The mean age of the adolescents was 12.5 (SD 1.03) years. The groups did not differ significantly regarding age. Weight was significantly different among the groups of sports, with the adolescents in the mixed sports group presenting higher weight $(P=0 \cdot 01)$ than those in the endurance and strength-skill group. Height is significant in the ANOVA test $(P=0 \cdot 04)$, but the RyanEinot-Gabriel-Welsch multiple range test is less conservative and did not distinguished differences among the sports groups. Table 1 also shows the mean amount of time spent in training per week: the individuals in the endurance sports group trained for longer periods than those in the strengthskill group, and the strength-skill group trained longer than the mixed sports groups $(P<0 \cdot 001)$. There were interactions of sex and sport for training time per week as females trained longer than males, and males and females in mixed sports trained less. Percentage body fat was higher among females when compare to males and female athletes in endurance sports presented less body fat than girls engaged in strengthskill and mixed sports. There were no statistical differences in BMI among adolescents from the different sports groups and sex.

Table 1. Anthropometric characteristics and time spent in training of adolescents from the

\begin{tabular}{|c|c|c|c|c|c|c|c|}
\hline & \multicolumn{6}{|c|}{ Sports groups } & \multirow[b]{3}{*}{$P$ value } \\
\hline & \multicolumn{2}{|c|}{ Endurance } & \multicolumn{2}{|c|}{ Strength-skill } & \multicolumn{2}{|c|}{ Mixed } & \\
\hline & Mean & SD & Mean & SD & Mean & SD & \\
\hline Total group $(n)$ & \multicolumn{2}{|c|}{49} & \multicolumn{2}{|c|}{109} & \multicolumn{2}{|c|}{168} & \\
\hline Age (years) & $12 \cdot 4$ & 0.9 & $12 \cdot 5$ & 1.0 & $12 \cdot 5$ & 1.0 & 0.73 \\
\hline Weight (kg) & $46 \cdot 7^{\mathrm{a}}$ & 7.5 & $46 \cdot 6^{\mathrm{a}}$ & 9.8 & $50 \cdot 1^{\mathrm{b}}$ & 11.4 & 0.01 \\
\hline Height $(\mathrm{m})$ & 1.57 & 0.07 & 1.56 & 0.1 & 1.59 & 0.1 & 0.04 \\
\hline BMI $\left(\mathrm{kg} / \mathrm{m}^{2}\right)$ & 19.5 & $2 \cdot 6$ & $19 \cdot 3$ & 2.9 & $19 \cdot 2$ & $2 \cdot 7$ & 0.77 \\
\hline Body fat (\%) & $18 \cdot 0$ & $5 \cdot 2$ & $18 \cdot 6$ & $6 \cdot 7$ & 17.5 & $7 \cdot 3$ & 0.40 \\
\hline Training (h/week) & $11 \cdot 1^{\mathrm{a}}$ & 4.7 & $8.9^{\mathrm{b}}$ & 6.5 & $5 \cdot 1^{\mathrm{C}}$ & 2.5 & $<0.001$ \\
\hline Male $(n)$ & \multicolumn{2}{|c|}{23} & \multicolumn{2}{|c|}{60} & \multicolumn{2}{|c|}{121} & \\
\hline Age (years) & $12 \cdot 4$ & 0.8 & $12 \cdot 5$ & 1.0 & $12 \cdot 4$ & $1 \cdot 1$ & 0.91 \\
\hline Weight (kg) & $45 \cdot 4^{\mathrm{a}}$ & $7 \cdot 0$ & $46 \cdot 3^{\mathrm{ab}}$ & 9.5 & $50.0^{\mathrm{b}}$ & $12 \cdot 0$ & 0.04 \\
\hline Height (m) & 1.56 & 0.08 & 1.57 & 0.1 & 1.59 & 0.12 & 0.23 \\
\hline $\mathrm{BMI}\left(\mathrm{kg} / \mathrm{m}^{2}\right)$ & $20 \cdot 1$ & 2.6 & $19 \cdot 3$ & 2.9 & $18 \cdot 9$ & 2.5 & 0.13 \\
\hline Body fat $(\%)^{*}$ & $16 \cdot 0$ & $4 \cdot 2$ & $16 \cdot 9$ & $6 \cdot 7$ & $15 \cdot 0$ & 5.7 & 0.13 \\
\hline Training (h/week) $\dagger$ & $10 \cdot 4^{\mathrm{a}}$ & $5 \cdot 0$ & $7 \cdot 2^{\mathrm{b}}$ & 4.4 & $5 \cdot 0^{\mathrm{C}}$ & $2 \cdot 7$ & $<0.001$ \\
\hline Female $(n)$ & \multicolumn{2}{|c|}{26} & \multicolumn{2}{|c|}{49} & \multicolumn{2}{|c|}{47} & \\
\hline Age (years) & $12 \cdot 5$ & 1.0 & $12 \cdot 5$ & $1 \cdot 1$ & $12 \cdot 9$ & 1.0 & 0.17 \\
\hline Weight (kg) & $47 \cdot 8$ & 8.0 & 47.0 & $10 \cdot 4$ & 50.4 & 9.8 & 0.20 \\
\hline Height (m) & 1.59 & 0.07 & 1.55 & 0.09 & 1.59 & 0.08 & 0.05 \\
\hline $\mathrm{BMI}\left(\mathrm{kg} / \mathrm{m}^{2}\right)$ & 18.9 & 2.5 & $19 \cdot 3$ & 2.9 & $19 \cdot 8$ & 3.0 & 0.42 \\
\hline Body fat $(\%)^{*}$ & $19 \cdot 7^{a}$ & 5.5 & $20 \cdot 7^{\mathrm{b}}$ & 7.6 & $23 \cdot 8^{\mathrm{b}}$ & $5 \cdot 0$ & 0.01 \\
\hline Training (h/week) & $11 \cdot 7^{\mathrm{a}}$ & 4.5 & $11 \cdot 1^{\mathrm{a}}$ & 8.0 & $5 \cdot 3^{\mathrm{b}}$ & $2 \cdot 3$ & $<0.001$ \\
\hline
\end{tabular}

a,b,c Mean values within a row with unlike superscript letters were significantly different $(P \leq 0.05)$.

* Significant interaction $(P=0.002)$ between $\operatorname{sex}(P<0.001)$.

† Significant interactions $(P=0.008)$ between sex $(P=0.001)$ and sport $(P<0.001)$. 
Table 2 shows the mean energy and macronutrient intake values of the adolescents grouped by sports and by sport and sex. Total energy expenditure was higher for adolescents engaged in endurance sports when compared to strength-skill and mixed sports. In the female group total energy expenditure differs among all sport groups. Energy intake did not differ significantly among the groups. Protein intake (in grams, and grams per unit body weight) was significantly higher for all adolescents in the endurance sport group when compared to the other two groups. Female endurance adolescents present

Table 2. Total energy expenditure (TEE), total energy intake (TEI) and macronutrient intake of adolescents grouped by sports and sex from the Federal District, Brazil

\begin{tabular}{|c|c|c|c|c|c|c|c|}
\hline & & & Sports & oups & & & \\
\hline & Endu & & Stren & -skill & & & \\
\hline & Mean & SD & Mean & SD & Mean & SD & $P$ value \\
\hline All & $n 49$ & & $n 109$ & & $n 168$ & & \\
\hline TEE (kJ/d) & $10125^{a}$ & 2113 & $9054^{b}$ & 1929 & $8970^{b}$ & 1732 & $<0.001$ \\
\hline TEE (kcal/d) & $2420^{a}$ & 505 & $2164^{b}$ & 461 & $2144^{b}$ & 414 & $<0.001$ \\
\hline TEI $(\mathrm{kJ} / \mathrm{d})^{*}$ & 10477 & 3180 & 9439 & 2807 & 9849 & 2694 & 0.09 \\
\hline TEI $(\mathrm{kcal} / \mathrm{d})^{*}$ & 2504 & 760 & 2256 & 671 & 2354 & 644 & 0.09 \\
\hline Proteins* & & & & & & & \\
\hline g & $98^{a}$ & $28 \cdot 3$ & $86^{b}$ & $26 \cdot 9$ & $89^{b}$ & $26 \cdot 7$ & 0.03 \\
\hline$\%$ TEI & 16 & 1.5 & 15 & $2 \cdot 1$ & 15 & $2 \cdot 27$ & 0.25 \\
\hline $\mathrm{g} / \mathrm{kg}$ body wt & $2 \cdot 2^{\mathrm{a}}$ & 0.76 & $1.9^{b}$ & 0.7 & $1.9^{b}$ & 0.74 & 0.04 \\
\hline Lipids* & & & & & & & \\
\hline$g$ & 96 & $36 \cdot 5$ & 88 & $28 \cdot 1$ & 91 & $27 \cdot 7$ & 0.41 \\
\hline$\%$ TEI & 32 & 3.85 & 33 & $3 \cdot 2$ & 33 & $3 \cdot 34$ & 0.70 \\
\hline g/kg body wt & $2 \cdot 1$ & 0.96 & 1.9 & 0.76 & 1.9 & 0.73 & 0.39 \\
\hline Carbohydrates* & & & & & & & \\
\hline $\mathrm{g}$ & 309 & $85 \cdot 4$ & 281 & $85 \cdot 7$ & 295 & $83 \cdot 5$ & 0.10 \\
\hline$\%$ TEI & 51 & 3.77 & 51 & $3 \cdot 6$ & 51 & 3.9 & 0.89 \\
\hline g/kg body wt & $6 \cdot 8$ & $2 \cdot 44$ & $6 \cdot 3$ & $2 \cdot 4$ & $6 \cdot 3$ & $2 \cdot 33$ & 0.31 \\
\hline Male & $n 23$ & & $n 60$ & & $n 121$ & & \\
\hline TEE (kJ/d) & $11309^{a}$ & 2498 & $9648^{b}$ & 2159 & $9422^{b}$ & 1757 & $<0.001$ \\
\hline TEE (kcal/d) & $2703^{a}$ & 597 & $2306^{b}$ & 516 & $2252^{b}$ & 420 & $<0.001$ \\
\hline $\operatorname{TEI}(\mathrm{kJ} / \mathrm{d})^{*}$ & 10966 & 3062 & 10200 & 2920 & 10196 & 2745 & 0.47 \\
\hline TEI $(\mathrm{kcal} / \mathrm{d})^{*}$ & 2621 & 732 & 2438 & 698 & 2437 & 656 & 0.47 \\
\hline Proteins* & & & & & & & \\
\hline$g$ & 103 & $26 \cdot 8$ & 95 & $27 \cdot 4$ & 94 & $27 \cdot 2$ & 0.30 \\
\hline$\%$ TEI & 16 & 1.5 & 16 & 1.9 & $15 \cdot 8$ & $2 \cdot 2$ & 0.70 \\
\hline g/kg body wt & $2 \cdot 3$ & 0.6 & $2 \cdot 1$ & 0.8 & $2 \cdot 0$ & 0.8 & 0.10 \\
\hline Lipids* & & & & & & & \\
\hline $\mathrm{g}$ & 100 & $33 \cdot 4$ & 95 & 30 & 94 & 28 & 0.64 \\
\hline$\%$ TEI & 33 & 3.7 & 33 & $3 \cdot 1$ & 33 & 3.4 & 0.99 \\
\hline g/kg body wt & $2 \cdot 2$ & 0.7 & $2 \cdot 1$ & 0.8 & $2 \cdot 0$ & 0.8 & 0.36 \\
\hline Carbohydrates* & & & & & & & \\
\hline$g$ & 321 & $87 \cdot 4$ & 300 & $88 \cdot 4$ & 304 & $85 \cdot 0$ & 0.62 \\
\hline$\%$ TEI & 51 & $3 \cdot 8$ & 51 & 3.6 & 51 & 3.7 & 0.85 \\
\hline g/kg body wt & $7 \cdot 1$ & $2 \cdot 2$ & $6 \cdot 8$ & $2 \cdot 4$ & $6 \cdot 5$ & 2.4 & 0.55 \\
\hline Female & $n 26$ & & $n 49$ & & $n 47$ & & \\
\hline TEE $(k J / d)$ & $9075^{a}$ & 808 & $8326^{b}$ & 1293 & $7799^{c}$ & 967 & $<0.001$ \\
\hline TEE $(\mathrm{kcal} / \mathrm{d})$ & $2169^{a}$ & 193 & $1990^{b}$ & 309 & $1864^{c}$ & 231 & $<0.001$ \\
\hline $\operatorname{TEI}(\mathrm{kJ} / \mathrm{d})^{*}$ & $10046^{a}$ & 3280 & $8502^{b}$ & 2377 & $8954^{b}$ & 2394 & 0.05 \\
\hline TEI $(\mathrm{kcal} / \mathrm{d})^{*}$ & $2401^{a}$ & 784 & $2032^{b}$ & 568 & $2140^{b}$ & 565 & 0.05 \\
\hline Proteins* ${ }^{*}$ & & & & & & & \\
\hline$g$ & $92^{\mathrm{a}}$ & 29 & $74^{b}$ & 22 & $77^{\mathrm{b}}$ & 22 & 0.006 \\
\hline$\%$ TEI & 16 & 1.7 & 15 & $2 \cdot 3$ & 15 & $2 \cdot 4$ & 0.13 \\
\hline $\mathrm{g} / \mathrm{kg}$ body wt & $2 \cdot 0^{\mathrm{a}}$ & 0.9 & $1 \cdot 6^{\mathrm{b}}$ & 0.6 & $1 \cdot 6^{\mathrm{b}}$ & 0.6 & 0.02 \\
\hline Lipids* & & & & & & & \\
\hline $\mathrm{g}$ & 91 & 39 & 80 & 23 & 82 & 25 & 0.23 \\
\hline$\%$ TEI & 32 & $4 \cdot 0$ & 33 & 3.4 & 33 & $3 \cdot 3$ & 0.55 \\
\hline g/kg body wt & $2 \cdot 1$ & $1 \cdot 1$ & 1.8 & 0.7 & $1 \cdot 7$ & 0.7 & 0.23 \\
\hline Carbohydrates* & & & & & & & \\
\hline$g$ & 300 & 84 & 258 & 77 & 273 & 76 & 0.09 \\
\hline$\%$ TEI & 52 & $3 \cdot 8$ & 52 & 3.7 & 52 & $4 \cdot 3$ & 0.77 \\
\hline $\mathrm{g} / \mathrm{kg}$ body wt & $6 \cdot 6$ & $2 \cdot 7$ & $5 \cdot 7$ & $2 \cdot 3$ & $5 \cdot 7$ & 1.9 & 0.20 \\
\hline
\end{tabular}

a,b,c Mean values within a row with unlike superscript letters were significantly different $(P \leq 0.05)$.

* Intake of energy and nutrients were corrected for intra-individual variation. 
higher protein intake than girls in the strength-skill and mixed sports. There were no significant differences in the intake of the remaining macronutrients. Macronutrient intake, when expressed as percentage of total energy, did not significantly differ among the adolescents in the three groups of sports. Mean macronutrient intake expressed as percentage of total energy for the adolescents in the present study was within the acceptable macronutrient distribution range of $10-35 \%$ for proteins, $45-65 \%$ for carbohydrates and $25-35 \%$ for lipids $^{(1)}$.

The food frequency intake analysis was adjusted in accordance with the groups of the Brazilian food pyramid ${ }^{(17)}$. The food groups and portions per day for the Brazilian food pyramid are: cereals, bread, pasta and tubers, five to nine portions; fruits, three to five portions; vegetables, four to five portions; legumes or pulses, one portion; meats and eggs, one to two portions; milk and dairy products, three portions; sugar and sweets, one to two portions; lipids and oils, one to two portions. Among the adolescents of the present study, there was a high intake of sweets; convenience foods (high-energy, low-nutrient density foods) such as chips, hot dogs, pizza, popcorn, dips; and fats and oils. Convenience foods and sweets frequency intake was 4.8 portions per day. Fats and oils frequency intake was $2 \cdot 8$ portions per day. There was also an insufficient intake of vegetables (one portion per day). Intake of cereal; meat, poultry and eggs; milk and dairy products; and legumes was five; two; 1.5; and one portion(s) per day, respectively.

Data analysis for micronutrients, fibre and water intake were performed on the whole group as there are no established reference values according to types of sport. Data were also separated by sex. Fibre and water intake were assessed by AI and are presented in Table 3. The interpretation for nutrients whose reference intake is based on AI values is different from the interpretation of nutrients with an EAR. In this case, individuals whose intake is above the AI value for a given nutrient are most likely to be consuming adequate amounts of the nutrient. More fibre than the AI was ingested by $2 \%$ of the adolescents and $4.6 \%$ of the adolescents ingested more liquids (including water) than the AI. The proportion of individuals ingesting safe amounts total water (pure water, beverages and water present in foods) reached $78 \%$ of the adolescents. When separated by sex, female adolescents present a higher percentage of individuals with liquids and water intake than males. It is not possible to state that the adolescents whose fibre and water intake have not reached the AI values were not consuming adequate amounts.

Table 4 shows the mean and standard deviation for micronutrient intake and the prevalence of nutrient intake adequacy according to EAR or AI values for the intake data corrected for intra-individual variation. Results are presented for all adolescents and separated for each sex. In a normal distribution, the percentage of individuals with adequacy of intake should be $97-98 \%(E A R+2 S D)$. Vitamins $A$ and $B_{12}$ and the minerals copper and iron presented adequacy of intake with a percentage equal to or above $97 \%$ among the adolescents of both sexes. Vitamins $\mathrm{B}_{2}$ and $\mathrm{C}$ and the mineral zinc presented high percentages of adequacy (between 92 and $96.9 \%$ ) for the studied group and in male and females. Vitamins $\mathrm{B}_{6}$ and niacin had percentages of adequacy above $93 \%$ for males but were below this level for females.

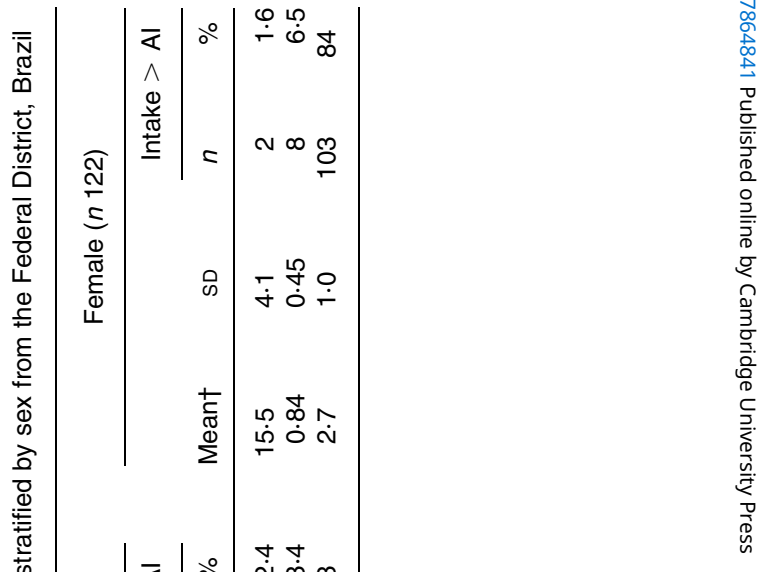


Table 4. Mean intake corrected for intra-individual variation and prevalence of adequate nutrient intake (Al) of all adolescents and stratified by sex from the Federal District, Brazil

\begin{tabular}{|c|c|c|c|c|c|c|c|c|c|c|c|c|c|c|}
\hline \multirow[b]{3}{*}{ Nutrient } & \multicolumn{2}{|c|}{$\mathrm{EAR} / \mathrm{Al}^{*}$} & \multicolumn{4}{|c|}{ All $(n$ 326) } & \multicolumn{4}{|c|}{ Male $(n$ 204) } & \multicolumn{4}{|c|}{ Female $(n 122)$} \\
\hline & \multirow[b]{2}{*}{ Age $<14$ years } & \multirow[b]{2}{*}{ Age $\geq 14$ years } & \multirow[b]{2}{*}{ Mean } & \multirow[b]{2}{*}{ SD } & \multicolumn{2}{|c|}{$\begin{array}{l}\text { Intake }> \\
\text { EAR/AI }\end{array}$} & \multirow[b]{2}{*}{ Mean } & \multirow[b]{2}{*}{ SD } & \multicolumn{2}{|c|}{$\begin{array}{c}\text { Intake > } \\
\text { EAR/AI }\end{array}$} & \multirow[b]{2}{*}{ Mean } & \multirow[b]{2}{*}{ SD } & \multicolumn{2}{|c|}{$\begin{array}{c}\text { Intake }> \\
\text { EAR/AI }\end{array}$} \\
\hline & & & & & $n$ & $\%$ & & & $n$ & $\%$ & & & $n$ & $\%$ \\
\hline Vitamin $B_{1}(\mathrm{mg} / \mathrm{d})$ & 0.7 & $0.9-1.0$ & 1.0 & 0.4 & 241 & 74 & $1 \cdot 1$ & 0.5 & 159 & 78 & 0.9 & 0.3 & 81 & 67 \\
\hline Vitamin $B_{2}(\mathrm{mg} / \mathrm{d})$ & 0.8 & $0.9-1.1$ & 1.4 & 0.4 & 309 & 95 & 1.6 & 0.5 & 194 & 95 & 1.3 & 0.4 & 115 & 94 \\
\hline Niacin $(\mathrm{mg} / \mathrm{d})$ & 9 & $11-12$ & $16 \cdot 2$ & 5.4 & 302 & 92 & 17 & 5.5 & 192 & 94 & 15 & $5 \cdot 1$ & 110 & 90 \\
\hline Vitamin $B_{6}(\mathrm{mg} / \mathrm{d})$ & 0.8 & $1 \cdot 0-1 \cdot 1$ & 1.6 & 0.5 & 296 & 91 & 1.7 & 0.6 & 189 & 93 & 1.5 & 0.6 & 107 & 88 \\
\hline Vitamin $B_{12}(\mathrm{mg} / \mathrm{d})$ & 1.5 & $2 \cdot 0$ & 5.9 & $2 \cdot 9$ & 319 & 98 & 6.4 & $3 \cdot 1$ & 201 & 99 & $5 \cdot 2$ & $2 \cdot 3$ & 118 & 97 \\
\hline Folate ( $\mu \mathrm{g} / \mathrm{d}$ per DFE) & 250 & 330 & 188 & 62 & 37 & 11 & 197 & 66 & 29 & 14 & 174 & 52 & 8 & 7 \\
\hline Vitamin C (mg/d) & 39 & $56-63$ & 140 & 79 & 311 & 95 & 143 & 80 & 194 & 95 & 136 & 77 & 117 & 96 \\
\hline Vitamin A $(\mu \mathrm{g} / \mathrm{d})$ & $420-445$ & $485-630$ & 1024 & 369 & 320 & 98 & 1044 & 391 & 199 & 98 & 991 & 330 & 121 & 99 \\
\hline Vitamin E (mg/d) & 9 & 12 & 12 & $6 \cdot 2$ & 215 & 66 & 13 & 5.9 & 144 & 71 & 12 & $6 \cdot 7$ & 71 & 58 \\
\hline Calcium $(\mathrm{mg} / \mathrm{d}) \dagger$ & 1300 & 1300 & 774 & 275 & 15 & 5 & 809 & 282 & 12 & 6 & 715 & 255 & 3 & 2 \\
\hline Manganese $(\mathrm{mg} / \mathrm{d}) \dagger$ & $1.6-1.9$ & $1 \cdot 6-2 \cdot 2$ & 3.0 & 0.7 & 313 & 96 & $3 \cdot 2$ & 0.8 & 196 & 96 & $2 \cdot 7$ & 0.7 & 117 & 96 \\
\hline Magnesium (mg/d) & 200 & $300-340$ & 306 & 84 & 249 & 76 & 322 & 89 & 164 & 80 & 279 & 67 & 85 & 71 \\
\hline Phosphorus (mg/d) & 1055 & 1055 & 1248 & 350 & 224 & 69 & 1317 & 355 & 159 & 78 & 1134 & 311 & 65 & 53 \\
\hline Iron (mg/d) & $5.7-5.9$ & $7 \cdot 9-7.7$ & $14 \cdot 2$ & 4.2 & 322 & 99 & $15 \cdot 1$ & $4 \cdot 1$ & 204 & 100 & $12 \cdot 8$ & 4.0 & 118 & 97 \\
\hline Zinc (mg/d) & $7 \cdot 0$ & $7.3-8.5$ & $12 \cdot 3$ & $6 \cdot 1$ & 308 & 94 & $13 \cdot 3$ & 4.2 & 195 & 96 & $10 \cdot 8$ & 3.3 & 113 & 93 \\
\hline Copper (mg/d) & 0.54 & 0.685 & $2 \cdot 1$ & 0.5 & 326 & 100 & $2 \cdot 2$ & 0.6 & 204 & 100 & $2 \cdot 0$ & 0.5 & 122 & 100 \\
\hline
\end{tabular}

DFE, dietary folate equivalent; EAR, estimated average requirement.

*Where values are ranges the first value is for females and the second value is for males.

tThe reference values for calcium and manganese are Al. 
The nutrients whose percentages of adequacy were below $84 \%$ are considered more likely to be under-consumed by adolescents. The vitamins with the lowest percentages of adequacy among these adolescents were vitamins $\mathrm{B}_{1}(74 \%), \mathrm{E}$ $(66 \%)$ and folate $(11 \%)$. For the minerals, we observed a percentage below $84 \%$ for magnesium $(76 \%)$ and phosphorus $(69 \%)$ among the studied adolescents. For all micronutrients with lower adequacy of intake the prevalence was always lower for females.

The interpretation for calcium and manganese is different since these nutrients have AI as reference value. Considering all athletes, $5 \%$ of the adolescents presented safe calcium intake levels. On the other hand, $96 \%$ of the individuals presented safe manganese intake levels. The number of adolescents with intake above the AI is again higher for males than for females. Once more, it is not possible to state that the individuals whose calcium and manganese intake do not reach the AI values ingest inadequate amounts of these nutrients.

Zinc was the only element that presented intake above the upper tolerable nutrient intake by $1.3 \%$ of the sample, that is four adolescents. As for vitamins, only niacin was ingested above the upper tolerable nutrient intake in the form of supplements, with a percentage of subjects below $1 \%$ (two individuals).

Supplements were taken by $23 \%$ of the adolescents in the present study, and most of these supplements were in the form of sport drinks (50.6\%). Only sixteen adolescents in the study used vitamin and mineral supplements.

\section{Discussion}

This was a cross-sectional study that assessed the nutrient and water intake of adolescents engaged in sports training. The micronutrient, water and fibre intake data were analysed according to recent concepts of nutritional references proposed by the Food and Nutrition Board and Institute of Medicine committees $^{(6,18)}(2000-2004)$. Macronutrient intake was analysed in absolute values, values relative to body weight and as a percentage of total energy, and compared with reference values reported by the $\mathrm{ACSM}^{(2)}$ and by the Institute of Medicine $^{(1)}$. For this analysis, the adolescents were grouped into endurance, strength-skill and mixed sports. Analysis was also conducted to assess differences with regards to sex.

A primary concern in nutrition is the delivery of adequate energy, especially for young athletes ${ }^{(19,20)}$. Adolescents in endurance sports present significantly higher training time and also significant total energy expenditure. Total energy intake was significantly higher for endurance female athletes. Anthropometric data show that mean weight, height and BMI were within the normal range for age.

Carbohydrate intake relative to body weight was within the values recommended by the $\mathrm{ACSM}^{(2)}$ for male athletes $(6-10 \mathrm{~g} / \mathrm{kg}$ body weight). Girls in strength-skill and mixed sports, however, did not fulfil this level of intake. Mean protein intake of male athletes in all three sports groups was above reference values reported by the ACSM $(1.2-1.6 \mathrm{~g} / \mathrm{kg}$ body weight for endurance and $1.4-1.7 \mathrm{~g} / \mathrm{kg}$ body weight for strength). Girls engaged in endurance sports also present high protein intake when compared to girls in the strength-skill and mixed sports. The intake levels of protein established by the
ACSM consider the high requirement of protein for athletes and there is no benefit to adopt a high level of protein intake ${ }^{(2)}$.

The low consumption of whole cereals as well as fruits and vegetables was reflected by the low prevalence of fibre intake above the AI. Water intake also had a low proportion of adequacy. Low fibre intake associated with low water intake has potential health risks ${ }^{(6)}$. However, it is not possible to state that some individuals presented inadequate intake, since the EAR for water has not been estimated yet. Physical activity and environmental factors greatly influence the water requirement of adolescents ${ }^{(18,20)}$. Therefore, in this group, water intake should be increased for the adolescents to remain as close as possible to the safe levels. Bar-Or ${ }^{(21)}$ reported that child and adolescent athletes drink more water if the water is flavoured and contains carbohydrates and table salt, and that this may be an important strategy to keep this group adequately hydrated. In this respect, the adolescents in the present study ingested liquids in the form of juices and soft drinks, which contribute both to water intake and also to their energy intake.

In the micronutrient intake assessment, most of the analysed nutrients were ingested in adequate amounts, that is ten out of sixteen nutrients examined. These nutrients were selected because EAR or AI values are available. Vitamin $\mathrm{B}_{1}$, vitamin $\mathrm{E}$, folate, calcium, magnesium and phosphorus presented low prevalence of adequacy for either male or female athletes, and results were consistently lower for females. Additionally, female athletes trained more than males. Female adolescent athletes are at higher risk for nutritional deficiencies.

Low intake of micronutrients is of considerable concern as if maintained for certain periods of time this can result in deficiencies, which threaten health and performance ${ }^{(6,22)}$. On the other hand, there are limitations to nutritional assessment from dietary recalls and dietary analysis ${ }^{(6)}$. Vitamin E intake can be underestimated when lipid underreporting occurs. In the present study, the adolescents reported lipid intake in the normal range of the acceptable macronutrient distribution range and there was no specific absence of vegetable oils in their foods. Additionally, food composition tables are inconsistent in providing the amount of vitamin E present in raw, industrialized or prepared foods, which can lead to an erroneous conclusion of inadequate intake.

There is a relationship between energy intake and thiamin intake. Individuals with high energy intake, such as athletes, should have high thiamin intake as long as their food choices are appropriate ${ }^{(23)}$. Physical activity, under normal conditions, does not alter thiamin requirement. However, as physical activity becomes more intense, a higher thiamin intake might become necessary ${ }^{(24)}$. The adolescents did consume thiamin-containing foods, but not in sufficient quantities to achieve adequacy in relation to reference values. This is consistent with their high consumption ( 4.8 portions per day) of high-energy, but low-nutrient density foods.

Folate was the vitamin with the least prevalence of adequacy. This result is not surprising as it is recognized that food composition data contained in currently used databases provide inaccurate estimations of folate, as the values underestimate actual food folate content ${ }^{(24)}$. In addition, the intake of vegetables, one of the sources of food folate, observed among these adolescents was low. A policy of fortifying 
flour with folic acid has been approved in Brazil ${ }^{(25)}$, but the implementation of this policy began after this dietary survey was conducted (2005).

The AI of calcium, established by the DRI committee, seems to be enough to maintain safe intake levels of this nutrient. However, individuals who consume less than the AI may also be consuming enough calcium for their needs ${ }^{(26)}$. In the present study, the prevalence of adolescents consuming calcium at or above the AI was low. Also, the consumption of milk and dairy products was 1.5 portions per day. Ideally they should be consuming three portions of milk and dairy products per day to meet their daily needs. In the literature there is a report of low calcium intake due to low consumption of dairy products among Italian adolescents ${ }^{(27)}$. An increase in consumption of milk and dairy products should correct or ameliorate the low intake of calcium, and also contribute to magnesium intake. The number of female adolescents with intake above the AI was very small.

Phosphorus is present in sufficient amounts in all foods ${ }^{(26)}$. The increased intake of beverages like colas and other soft drinks, especially those that use phosphoric acid as acidifier, among the adolescents in the present study, should result in a proper phosphorus intake. As with vitamin $\mathrm{E}$, the absence of this element in food composition tables may have contributed to the apparent low intake, since there were no food restrictions that would justify this observation.

Cavadini et al. ${ }^{(28)}$ and Croll et al. ${ }^{(29)}$ compared groups of sedentary and sports-practising adolescents, and considered that the dietary habits of the athletes were healthier than those of the non-athletes. Among the athletes, fruits, fruit juices, cereals and salads were consumed in greater amounts ${ }^{(28)}$ and breakfast was eaten more frequently ${ }^{(29)}$. This was not the case in the present study, where the consumption of vegetables was low and monotonous, helping to explain the low micronutrient and fibre intakes found among the adolescents. Given the low intake of certain nutrients, there has been a suggestion that the use of dietary supplements should be widely encouraged among children and adolescents ${ }^{(30,31)}$. Other strategies have been developed to provide adequate nutrient intakes. These include the promotion of diversified diets and fruit and vegetable consumption by the WHO's global strategy ${ }^{(32)}$. The latter strategy is preferred over that of supplements because it does not incur unnecessary toxicity risks and also guarantees a bulk intake of nutritional compounds. Use of vitamins and mineral supplements was not prevalent for these adolescents, however, among those who did use supplements there was an intake above the upper tolerable nutrient intake for niacin and zinc.

Previous results published in the literature address the evaluation of adolescents' nutrient intakes. Croll et al. ${ }^{(29)}$ compared dietary data obtained from FFQ and found that youths participating in sports had higher mean intakes of protein, calcium, iron and zinc than youths not involved in sports training. Other studies involving adolescent athletes $^{(27,33,34)}$ compared the mean nutrient intake with the RDA and found that the mean intake of vitamins D, E and $\mathrm{B}_{6}$ and of the minerals magnesium, calcium, iodine and phosphorus was low. Although these earlier results are broadly consistent with the present findings, the studies cannot be directly compared and must be considered with caution given the different assessment methods used. Comparing the mean intake of a group with the RDA does not give the correct prevalence of adequacy ${ }^{(6)}$. When dietary assessment uses the DRI methodology it is possible to define the prevalence of dietary adequacy or inadequacy. Therefore, it is impossible to directly compare the present results with those of other researchers. Available data assessing the dietary intake of adolescent athletes are largely insufficient ${ }^{(35)}$. Recently, Schenkel et al. ${ }^{(36)}$ published results of nutritional assessment of adolescent males using the DRI methodology and found low prevalence of adequacy for vitamin A, B6, magnesium, phosphorus and zinc.

The present study assessed nutrient and water intake of a representative sample of adolescents engaged in sport training and competition. We employed the most recent reports and methodology from the Institute of Medicine and ACSM to compare the data, which strengthens the present results. To our knowledge this is the first report to assess water intake of adolescents and compare the results with recently published DRI values. Water intake was assessed by a dietary recall method, which is prone to recall bias ${ }^{(6)}$. Although implementation and application of the dietary recall instrument were performed following all adequate practice steps: team training, presentation of a picture guide and use of tools for the correct identification of the portions of foods consumed, the method has not yet been validate. In this respect, results should then be taken cautiously.

In conclusion, the present study, using DRI to assess dietary intake, showed that Brazilian adolescent athletes need further guidance in order to select foods coherently and therefore meet their water, fibre and some micronutrient needs, and avoid the risk of nutrient toxicity. This could be achieved by increasing consumption of milk, dairy products, vegetables, water and fibre-rich foods, while reducing the intake of protein from other food sources, such as meat. Male athletes fulfil carbohydrate intake levels but consumed levels of protein higher than the guidelines established by ACSM. Conversely, female athletes engaged in strengthskill and mixed sports did not reach adequate levels of carbohydrate intake. Also female athletes presented lower prevalence for micronutrient intake but longer training sessions than male adolescent athletes. The results from this research stress that nutritional education should be planned and delivered to adolescents, together with the promotion of physical activity and sports participation, for both talent selection and health outcomes. Sports federation and sports clubs should provide sound nutritional information to adolescents to avoid perpetuation of common dietary practice inappropriate to maintaining adequate nutritional intake.

\section{Acknowledgements}

We thank CNPq (Brazil) for the financial grant. We thank Clislian L. da Silva who participated in the interviewing and entered the dietary data. There is no conflict of interest. The roles of the authors in this study were as follows: experimental design, data collection and drafting of the manuscript: E. F. D. S. and J. A. D. N. Study concept and design, statistical analysis: L. J. V. Study concept and design, critical review of the manuscript for important intellectual content, fund raising and study supervision: T. H. M. D. C. 


\section{References}

1. Institute of Medicine (2002) Dietary Reference Intakes for Energy, Carbohydrate, Fiber, Fat, Fatty Acids, Cholesterol, Protein, and Amino Acids (Macronutrients). Washington, DC: National Academy Press.

2. American College of Sports Medicine, American Dietetic Association, Dietitians of Canada (2000) Nutrition and athletic performance. Med Sci Sports Exerc 32, 2130-2145.

3. Roemmich JN, Richmond EJ \& Rogol AD (2001) Consequences of sport training during puberty. $J$ Endocrinol Invest 24, 708-715.

4. Brasil Ministerio da Saude (2006) Politica Nacional de Promocao da Saude (National Policy for Health Promotion). Portaria no. 687, 30 March. http://www.saude.gov.br/svs

5. Brasil Ministerio do Esporte (2004) Descoberta do talento esportivo (Discovery of Sport Talents) http://www.esporte.gov. br/talento_esportivo

6. Institute of Medicine (2000) Dietary Reference Intakes Applications in Dietary Assessment. Washington, DC: National Academy Press.

7. Nogueira JAD, Da Costa THM \& Coward WA (2007) Anthropometry, bioelectrical impedance and ${ }^{2} \mathrm{H}_{2} \mathrm{O}$ measurements of body composition in Brazilian adolescents. Int $J$ Body Compos Res 5, 9-15.

8. Zabboto CB, Vianna RPT \& Gil MF (1996) Registro fotográfico para inquéritos dietéticos: utensílios e porções (Photographic Guide for Dietetic Recalls: Kitchen Utensils and Portions). Goiânia: RTN Gráfica e Editora.

9. Lohman TG, Roche AF \& Martorell R (1988) Anthropometric Standardization Reference Manual. Champaign, IL: Human Kinetics Publishers.

10. Boileau RA, Lohman TG \& Slaughter MH (1985) Exercise and body composition of children and youth. Scan J Sports Sci 7, $17-27$.

11. Pinheiro ABV, Lacerda EMA, Benzencry EH, Gomes MCS \& Costa VM (2000) Tabela para avaliação de consumo alimentar em medidas caseiras (Table for Food Intake Assessment in Cooking Measures). Rio de Janeiro: Atheneu.

12. Brasil Ministério da Saúde (2002) Alimentos regionais brasileiros (Brazilian Regional Food). Brasília: Ministério da Saúde.

13. Phillippi ST (2002) Tabela de composição de alimentos: suporte para decisão nutricional (Food Composition Table: Support for Nutritional Decision). São Paulo: Coronário.

14. Nusser SM, Carriquiry WA, Dodd KW \& Fuller WAA (1996) A semi-parametric transformation approach to estimating usual daily intake distribution. J Am Stat Assoc 91, 1440-1449.

15. Hoffmann K, Boeing H, Dufour A, Volatier JL, Telman J, Virtanen M, Becker W \& De Henauw S (2002) Estimating the distribution of usual dietary intake by short-term measurements. Eur J Clin Nutr 56, S53-S62.

16. SAS Institute Inc. (2003) SAS/STAT User Guide. Release 9.3. Cary, NC: SAS Institute.

17. Phillippi ST, Latterza AR, Cruz ATR \& Fisberg RM (1997) Pirâmide alimentar adaptada: um guia para escolha dos alimentos (Adapted food pyramid: a guide for food choice). Rev Nutr 12, 65-80.
18. Institute of Medicine (2004) Dietary Reference Intakes for Water, Potassium, Sodium, Chloride and Sulfate. Washington, DC: National Academy Press.

19. Thompson JL (1998) Energy balance in young athletes. Int $J$ Sport Nutr 8, 160-174.

20. Petrie HJ, Stover EA \& Horswill CA (2004) Nutritional concerns for the child and adolescent competitor. Nutrition 20 , $620-631$.

21. Bar-Or O (2001) Nutritional considerations for the child athlete. Can J Appl Physiol 26, S186-S191.

22. Gabel KA (2006) Special nutritional concerns for the female athlete. Curr Sports Med Rep 5, 187-191.

23. Manore MM (2000) Effect of physical activity on thiamine, riboflavin, and vitamin B6 requirements. Am J Clin Nutr 72, S598-S606.

24. Institute of Medicine (1998) Dietary Reference Intakes for Thiamin, Riboflavin, Vitamin $B_{6}$, Folate, Vitamin $B_{12}$, Pantothenic Acid, Biotin and Choline. Washington, DC: National Academy Press.

25. Agencia Nacional de Vigilancia Sanitaria (2002) $R D C$ no. 344 , 13 December. http://www.anvisa.gov.br/divulga/informes/2002/ 201202.htm

26. Institute of Medicine (1997) Dietary Reference Intakes for Calcium, Phosphorus, Magnesium, Vitamin D and Fluoride. Washington, DC: National Academy Press.

27. Cupisti A, D'Alessandro C, Castrogiovanni S, Barale A \& Morelli E (2002) Nutrition knowledge and dietary composition in Italian adolescent female athletes and non-athletes. Int $J$ Sport Nutr Exerc Metab 12, 207-219.

28. Cavadini C, Decarli B, Grin J, Narring F \& Michaud PA (2000) Food habits and sport activity during adolescence: differences between athletic and non-athletic teenagers in Switzerland. Eur J Clin Nutr 54, S16-S20.

29. Croll JK, Neumark-Sztainer D, Story M, Wall M, Perry C \& Harnack L (2006) Adolescents involved in weight-related and power team sports have better eating patterns and nutrient intakes than non-sport-involved adolescents. $J$ Am Diet Assoc 106, 709-717.

30. Benjamin M \& Ash D (2003) Drinking to their health: social analysis of a micronutrient-fortified beverage field trial. Food Nutr Bull 24, Suppl. 4, S141-S145.

31. Latham MC, Ash DM, Makola D, Tatala SR, Ndossi GD \& Mehansho H (2003) Efficacy trials of a micronutrient dietary supplement in schoolchildren and pregnant women in Tanzania. Food Nutr Bull 24, Suppl. 4, S120-S128.

32. World Health Organization/Food and Agriculture Organization of United Nations (2004) Fruit and Vegetable for Heath: Report of a Joint WHO/FAO Workshop, 1-3 September 2004, Kobe, Japan. Geneva: WHO.

33. Ziegler PJ, Khoo CS, Kris-Etherton PM, Jonnalagadda SS, Sherr B \& Nelson JA (1998) Nutritional status of nationally ranked Junior US figure skaters. J Am Diet Assoc 98, 809-811.

34. Weimann E (2002) Gender-related differences in elite gymnasts: the female athlete triad. $J$ Appl Physiol 92, 2146-2152.

35. Kern M (2006) Dietary intake of adolescent athletes and nonathletes. J Am Diet Assoc 106, 717-718.

36. Schenkel TC, Stockman NK, Brown JN \& Duncan AM (2007) Evaluation of energy, nutrient and dietary fiber intakes of adolescent males. J Am Coll Nutr 26, 264-271. 